\title{
Expression of the gap gene encoding glyceraldehyde-3-phosphate dehydrogenase of Streptomyces aureofaciens requires GapR, a member of the AraC/XyIS family of transcriptional activators
}

\author{
O. Sprušanský, B. Řežuchová, D. Homerová and J. Kormanec
}

Author for correspondence: J. Kormanec. Tel: +42175941 2432. Fax: +421 754772316. e-mail: umbijkor@savba.sk

Institute of Molecular Biology, Slovak Academy of Sciences, Dubravská cesta 21, 84251 Bratislava, Slovak Republic

\begin{abstract}
Expression of the gap gene encoding glyceraldehyde-3-phosphate dehydrogenase (GAPDH) is developmentally regulated, and induced by glucose in Streptomyces aureofaciens. A gene, gapR, encoding a protein similar to the AraC/XylS family of bacterial transcriptional regulators was identified upstream of gap. The gap $R$ gene was constitutively expressed from a single promoter during the course of differentiation. By integrative transformation, via double crossover, a stable null mutant of the gap $R$ gene was obtained. The mutation only slightly affected growth, and had no effect on differentiation of S. aureofaciens. However, transcription of the GAPDH-encoding gap gene was substantially reduced in the $S$. aureofaciens $\triangle$ gapR null mutant, irrespective of carbon source used. Though GAPDH activity was about 1.5-fold lower in the mutant, the substantial enzyme activity remained, suggesting the presence of a second GAPDH which is sufficient to ensure growth. The GapR protein, overproduced in Escherichia coli, was shown to bind upstream of the gap-P promoter region. The results indicate a direct role of GapR in regulation of gap expression in S. aureofaciens.
\end{abstract}

Keywords: glucose induction, differentiation, GAPDH, promoter, S1-nuclease mapping

\section{INTRODUCTION}

Glyceraldehyde-3-phosphate dehydrogenase (GAPDH) (EC 1.2.1.12), a key enzyme of glycolysis, plays a crucial role in catabolic and anabolic carbohydrate metabolism. It reversibly catalyses the oxidative phosphorylation of D-glyceraldehyde 3-phosphate to 1,3-bisphosphoglycerate using $\mathrm{NAD}^{+}$as a coenzyme (Harris \& Waters, 1976). Although GAPDH-encoding genes have been identified in various bacteria, detailed study of regulation has been done mainly in Escherichia coli. It contains two functional gap genes, gapA and gapB. In spite of the fact that the gapB gene is located in an operon with the other glycolytic gene, $p g k$, encoding phosphoglycerate kinase, a very low phosphorylating GAPDH activity was measured for this gene product,

Abbreviations: GAPDH, glyceraldehyde-3-phosphate dehydrogenase; tsp, transcription start point(s); wt, wild-type.

The GenBank/EMBL/DDBJ accession number for the sequence described in this paper is U21191. and it displayed high nonphosphorylating erythrose4-phosphate dehydrogenase activity (Alefounder \& Perham, 1989; Boschi-Muller et al., 1997). Since a mutation in the gapA gene abolished the GAPDH activity, the gapA gene was considered to be the only active GAPDH-encoding gene in E. coli (Branlant et al., 1983; Della Seta et al., 1997). Analysis of gapA transcription revealed a complex regulation comprising four tandemly organized promoters (Charpentier \& Branlant, 1994). The gapB-pgk operon is directed by a single promoter (Charpentier et al., 1998). Interestingly, expression of both gap genes is strongly stimulated by the presence of glucose in the medium, and this induction depends upon a component of the phosphoenolpyruvate-dependent phosphotransferase system (PTS), the EII ${ }^{\mathrm{Glc}}$ glucose-permease protein (Charpentier et al., 1998). Recently, glucose induction of gapA expression was also demonstrated in the low-GC Gram-positive bacterium Bacillus subtilis. This induction has been shown to depend indirectly on a key protein for catabolite repression, catabolite control protein (CcpA), 
which belongs to the LacI/GalR transcriptional repressor family (Fillinger et al., 2000; Tobisch et al., 1999).

Streptomycetes are mycelial, high-GC Gram-positive bacteria that undergo a complex cycle of morphological differentiation involving the development of sporebearing aerial hyphae on mycelial colonies. They produce a variety of biologically active secondary metabolites, including the majority of known antibiotics (Chater, 1998). Previously, we identified and characterized the GAPDH-encoding gap gene in Streptomyces aureofaciens (Kormanec et al., 1995). Transcriptional studies of the gap gene suggested monocistronic organization and developmental regulation of the gene. A single promoter, gap-P, was induced by the presence of glucose in the medium, and at the onset of aerial mycelium formation (Kormanec et al., 1997). Sequence analysis of the region upstream of gap has revealed the $3^{\prime}$ end of a gene encoding a protein similar to the AraC/XylS family of bacterial transcriptional regulators (Gallegos et al., 1997; Kormanec et al., 1995). Its close proximity to gap suggests a function in the regulation of gap expression, since transcriptional regulators of this family are usually located upstream of the operon they regulate (Gallegos et al., 1997). To elucidate a possible function of the gene, which we named gapR, in the regulation of gap expression in $S$. aureofaciens, we disrupted the gene and analysed expression of the gap gene under various conditions in this mutant. The GapR protein, overproduced in an E. coli expression system, was shown to bind upstream of the gap-P promoter region. The results suggest a direct role of GapR in regulation of gap expression in $S$. aureofaciens.

\section{METHODS}

Bacterial strains, plasmids and culture conditions. S. aureofaciens CCM 3239 wt was from the Czechoslovak Collection of Microorganisms, Brno, Czech Republic. E. coli XL1Blue (Stratagene) was used as a host, and plasmid pBluescript II $\mathrm{SK}(+)$ (Stratagene) was used for E. coli cloning experiments. E. coli expression plasmid pET28a was from Novagen. The overexpression was done in E. coli BL21(DE3)pLysS (Novagen). For protoplast preparation and DNA isolation, $S$. aureofaciens was cultured to late-exponential phase $(24 \mathrm{~h})$ in liquid TSB medium (Hopwood et al., 1985) containing $1 \%$ $(\mathrm{w} / \mathrm{v})$ maltose and $0.5 \%(\mathrm{w} / \mathrm{v})$ glycine as described by Kormanec et al. (1993). The phenotype of the $S$. aureofaciens $\triangle g a p R$ mutant was analysed after growth on solid minimal MM medium (Hopwood et al., 1985) and rich Bennet medium (Horinouchi et al., 1983) containing appropriate carbon source at $1 \%(\mathrm{w} / \mathrm{v})$ final concentration. For RNA isolation from liquid-grown cultures, $5 \times 10^{8}$ c.f.u. of $S$. aureofaciens strains were inoculated in $50 \mathrm{ml}$ liquid medium NMP (Hopwood et al., 1985) containing mannitol or glucose $(0.5 \%$, $\mathrm{w} / \mathrm{v}$ ) as a carbon source, and grown at $30^{\circ} \mathrm{C}$ to different growth phases: exponential phase, $12 \mathrm{~h}$; end of the exponential phase, $20 \mathrm{~h}$; and stationary phase, $30 \mathrm{~h}$. For RNA isolation from surface culture, $10^{8}$ c.f.u. of $S$. aureofaciens were spread on sterile cellophane membranes placed on Bennet medium (Horinouchi et al., 1983), and grown for $13 \mathrm{~h}$ (substrate mycelium), $19 \mathrm{~h}$ (the onset of aerial mycelium formation) and $36 \mathrm{~h}$ (aerial mycelium approximately at the time of septation). Conditions for E. coli growth and transformation are described by Ausubel et al. (1987).

DNA manipulations. DNA manipulations in E. coli were done as described in Ausubel et al. (1987), and those in Streptomyces were according to Hopwood et al. (1985). DNA fragments were isolated from agarose gels by binding to a DEAEpaper as recently described (Kormanec, 2000). Nucleotide sequencing was performed by the chemical method (Maxam \& Gilbert, 1980). Site-directed mutagenesis was done with a Chameleon mutagenesis kit from Promega.

Disruption of the gapR gene. The plasmid used for disruption of $S$. aureofaciens gapR was prepared as follows. Plasmid pRPO7-11C contained the 1170 bp BamHI-PstI fragment (Fig. 1a) bearing the full-length $S$. aureofaciens gap gene (Kormanec et al., 1995) in pBluescript SK $(+)$. This gapbearing insert was removed as a 1170 bp XhoI-XbaI (bluntended) fragment and inserted into XhoI- and SmaI-digested plasmid pTSR1 (Kormanec et al., 1998) containing the Streptomyces azureus tsr gene conferring resistance to thiostrepton, to create pRPO7-11S. The region upstream of the gapR gene was cloned as a $1250 \mathrm{bp} \mathrm{EcoRI-SmaI} \mathrm{fragment}$ (Fig. 1a) into EcoRI- and SmaI-digested plasmid pAPHII (Kormanec et al., 1998) containing the kanamycin-resistance gene of Tn5, to create pRPO7-11T. The resulting plasmid, pRPO7-11U, was prepared by inserting a 2400 bp XbaI-XhoI (blunt-ended) fragment from pRPO7-11S into pRPO7-11T cut with $\mathrm{XbaI}$ and $\mathrm{SacI}$ (blunt-ended). The plasmid pRPO7-11U was used to transform $S$. aureofaciens protoplasts as described by Kormanec et al. (1993). Thiostrepton-resistant clones were further analysed for thiostrepton resistance and kanamycin sensitivity, which might indicate a double crossover event. Two kanamycin-sensitive clones were identified, and correct integration was confirmed by Southern blot hybridization. Both clones had a similar phenotype, and one clone, $S$. aureofaciens $\triangle g a p R$, was chosen for further study.

RNA isolation and S1-nuclease mapping of the tsp. Total RNA was prepared from cultures of $S$. aureofaciens as recently described (Kormanec, 2000). The integrity of RNA was indicated by sharp rRNA bands after electrophoresis in agarose containing $2 \cdot 2 \mathrm{M}$ formaldehyde (Ausubel et al., 1987), and staining in ethidium bromide. High-resolution S1nuclease mapping was performed according to Kormanec (2000). Samples $(40 \mu \mathrm{g})$ of RNA (estimated spectrophotometrically) were hybridized to approximately $0.02 \mathrm{pmol}$ DNA probe labelled at one $5^{\prime}$ end with $\left[\gamma^{-32} \mathrm{P}\right]$ ATP (approx. $3 \times 10^{6}$ c.p.m. pmol $^{-1}$ ). The probes used (Fig. 1a) were: probe 1, a 1000 bp AgeI-BamHI fragment uniquely labelled on the $5^{\prime}$ end at the AgeI site; probe 2, a 580 bp Bsi WI-ApaLI fragment uniquely labelled on the $5^{\prime}$ end at the $B s i$ WI site. The $h r d B-P 2$ promoter probe has been described by Kormanec \& Farkašovský (1993). The protected DNA fragments were analysed on DNA sequencing gels together with $G+A$ and $\mathrm{T}+\mathrm{C}$ sequencing ladders derived from the end-labelled fragments (Maxam \& Gilbert, 1980).

Preparation of cell-free extracts. Liquid-grown S. aureofaciens mycelium was harvested by centrifugation at $12000 \mathrm{~g}$ for $10 \mathrm{~min}$, and washed by ice-cold STE buffer (10 mM Tris, $100 \mathrm{mM} \mathrm{NaCl}, 1 \mathrm{mM}$ EDTA, pH 8). The mycelium was disrupted by sonication on ice $(30 \mathrm{~min}$ total time, $30 \mathrm{~s}$ at amplitude 22 microns and $100 \mathrm{~s}$ pause; model Soniprep 150, MSE). Cell debris was then removed by centrifugation for $30 \mathrm{~min}$ at $30000 \mathrm{~g}$. The cell-free extracts were stored in aliquots at $-70^{\circ} \mathrm{C}$.

Protein analysis. Protein concentrations were determined according to Bradford (1976), with BSA as a standard. 
(a)
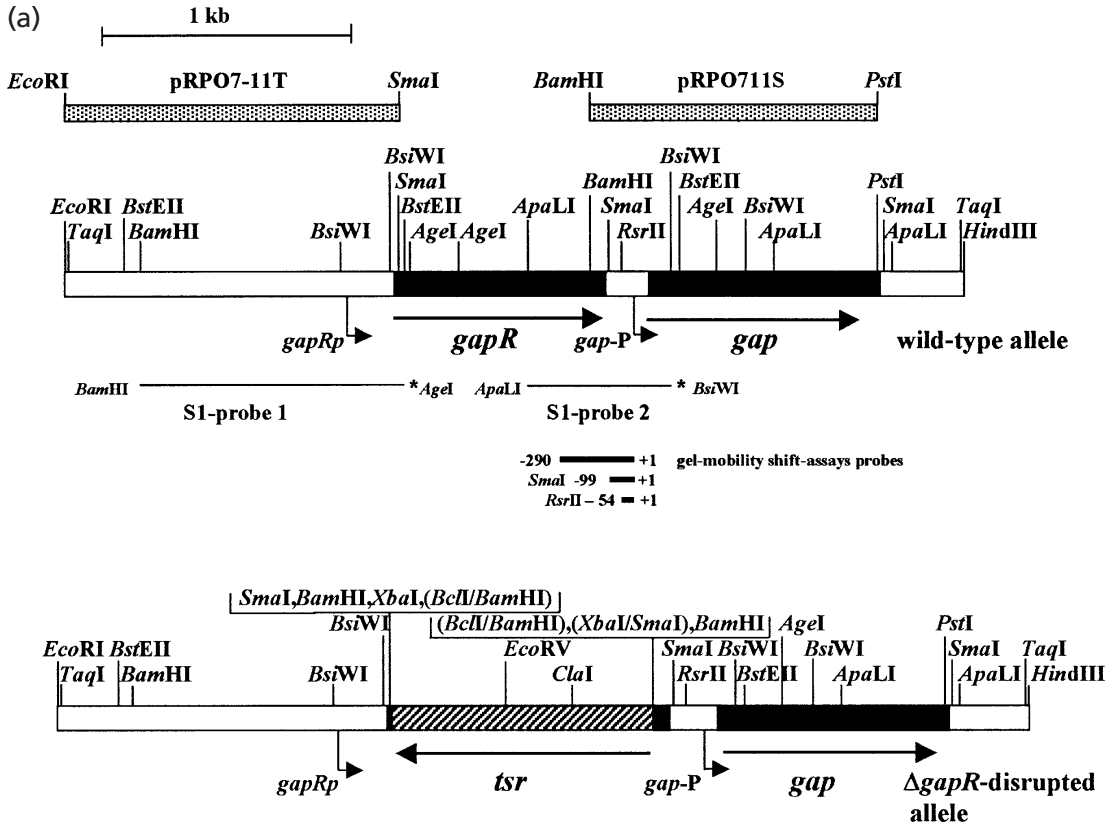

(b)

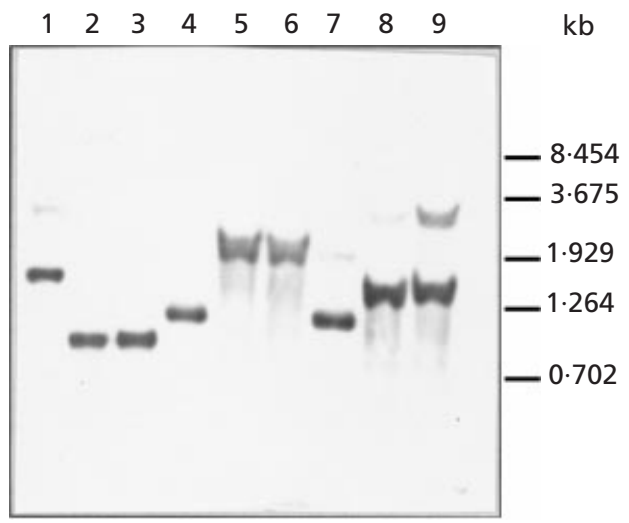

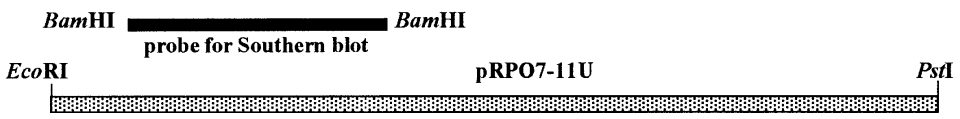

Fig. 1. (a) A $3.6 \mathrm{~kb}$ S. aureofaciens Taql chromosomal fragment (open box) containing the gapR and gap genes (black boxes), and chromosomal DNA of $S$. aureofaciens $\Delta g a p R$, disrupted by a thiostrepton-resistance gene (tsr) (hatched box) via double crossover. The positions of the fragments cloned in the plasmids used for gap $R$ disruption are shown by stippled boxes. The lines below the maps represent DNA fragments (5'-labelled at the end marked with asterisks) that were used as probes in S1-nuclease mapping. Bent arrows represent the direction of the apparent transcripts from gapRp and gap-P promoters. The black bars below the map of the wt allele represent DNA fragments $\left(5^{\prime}\right.$-labelled at the either end) that were used for gel mobility-shift assays and DNasel footprinting. Numbers indicate nucleotide positions relative to the tsp of the gap-P promoter. The black bar below the map of the $\Delta g a p R$-disrupted allele represents the probe (1000 bp BamHI-BamHI fragment from plasmid pRPO7-11U) used for Southern hybridization analysis. Relevant restriction sites are indicated. (b) Southern hybridization analysis of chromosomal DNA from the gene replacement experiments. Lanes: 1, BamHI-digested S. aureofaciens wt DNA; 2 and 3, BamHI-digested DNA from the two $S$. aureofaciens $\Delta$ gapR mutant strains; 4, BstEll-digested $S$. aureofaciens wt DNA; 5 and 6, BstEll-digested DNA from the two $S$. aureofaciens $\Delta$ gapR mutant strains; 7, BstEll +EcoRV-digested S. aureofaciens wt DNA; 8 and 9, BstEll +EcoRV-digested DNA from the two $S$. aureofaciens $\triangle g a p R$ mutant strains. Lambda DNA-BstEll digest was used as the molecular mass standard.

Denaturing SDS-PAGE of proteins was done as described by Laemmli (1970), and gels were stained with Coomassie blue R250. GAPDH was assayed by the arsenolysis procedure; 1 unit $(\mathrm{U})$ is defined as the amount of enzyme which reduces $1 \mathrm{mmol} \mathrm{NAD}^{+} \mathrm{min}^{-1}$ at $A_{340}$ (Byers, 1982).

Preparation of radiolabelled DNA fragments for GapRbinding studies. A 291 bp gap-P promoter DNA fragment (positions -290 to $+1 \mathrm{bp}$, in relation to the tsp of the gap-P promoter; Fig. 1a) was generated by PCR from plasmid pRPO7-11A (Kormanec et al., 1995). For labelling of a coding strand, a $5^{\prime}$-end-labelled oligonucleotide primer, mut73, internal to gapR (5'-CACCGGGTACACGCCGATGC-3') and an unlabelled oligonucleotide, mut75, from the gap-P promoter region (5'-CCACCAGGTTCCCCCGCTGG-3') were used. For labelling of a noncoding strand, oligonucleotide mut75 was $5^{\prime}$-end-labelled, and mut73 was unlabelled. The oligonucleotides were end-labelled with $[\gamma$ ${ }^{32} \mathrm{P}$ ]ATP (Amersham; $111 \mathrm{TBq} \mathrm{mmol}^{-1}$ ) and T4-polynucleotide kinase (Biolabs) as described in Ausubel et al. (1987). The labelled fragments were purified by PAGE as described in Kormanec (2000).
Gel mobility-shift assay. The assays were done as described by Ausubel et al. (1987). ${ }^{32}$ P-labelled DNA fragments $(0.5 \mathrm{ng}$, 5000-10000 c.p.m.) were incubated with cell-free extracts or partially purified GapR protein for $15 \mathrm{~min}$ at $30^{\circ} \mathrm{C}$ in $15 \mu \mathrm{l}$ total volume of the binding buffer $(12.5 \mathrm{mM}$ Tris $\mathrm{pH} 7 \cdot 9$, $60 \mathrm{mM} \mathrm{KCl}, 1 \mathrm{mM}$ EDTA, $1 \mathrm{mM}$ DTT, $12 \%$ glycerol) with $2 \mu \mathrm{g}$ sonicated salmon sperm DNA and $4.5 \mu \mathrm{g}$ BSA added. After incubation, protein-bound and free DNA were resolved on nondenaturing polyacrylamide gels $(4 \%$ acrylamide, $0.05 \%$ bisacrylamide and $2.5 \%$ glycerol), running in a highionic-strength buffer $(50 \mathrm{mM}$ Tris, $380 \mathrm{mM}$ glycine and $2 \mathrm{mM}$ EDTA, $\mathrm{pH} 8.5)$ at $4{ }^{\circ} \mathrm{C}$. The gels were dried and exposed to an $\mathrm{X}$-ray film.

DNasel footprinting. Binding reactions were performed under the same conditions as for the gel mobility-shift assays with 4 ng ${ }^{32}$ P-labelled DNA fragments (10000-30000 c.p.m.), in $30 \mu \mathrm{l}$ binding buffer. After incubation, $3 \mu \mathrm{l}$ DNase I solution [5 U DNase I ml ${ }^{-1}$ (Boehringer Mannheim) in $100 \mathrm{mM} \mathrm{MgCl}_{2}$, $100 \mathrm{mM} \mathrm{DTT}]$ was added to the binding reaction. The reaction mixture was incubated for $40 \mathrm{~s}$ at $37^{\circ} \mathrm{C}$, and stopped 


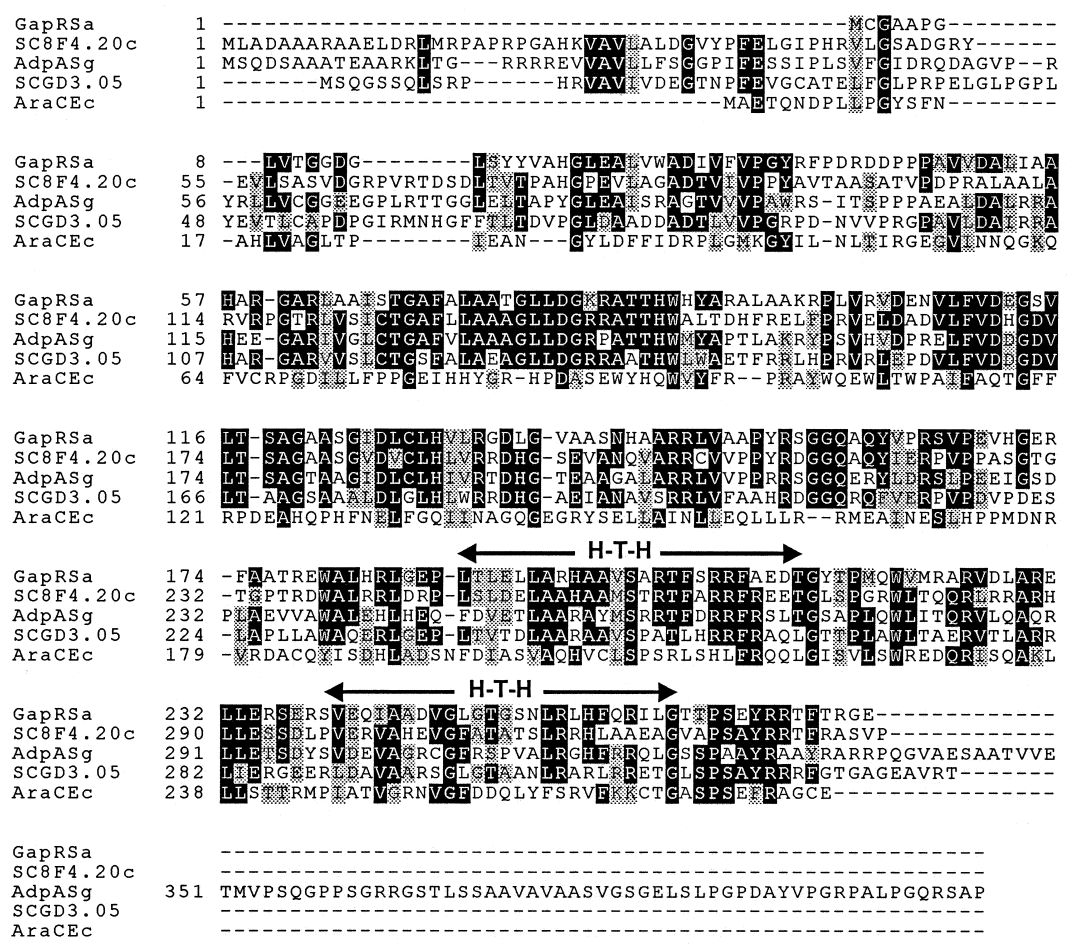

Fig. 2. Amino acid sequence alignment of S. aureofaciens GapR (GapRSa), S. griseus AdpA (AdpASg) (Ohnishi et al., 1999), two S. coelicolor AraC-like proteins (SC8F4.20C, SCGD3.05) (accession nos AL137242 and AL096822, respectively) and E. coli AraC (AraCEc) (accession no. SP:P03021). The positions of two $\alpha$-helix-turn- $\alpha$-helix (HTH) DNA-binding motifs are denoted by arrows above the sequence. Identical residues are highlighted in black. Similar residues are shaded. The numbers indicate amino acid positions.

with $7 \cdot 5 \mu \mathrm{l}$ DNase I stop buffer ( $3 \mathrm{M}$ ammonium acetate, 0.25 M EDTA, $0 \cdot 1 \mathrm{mg}$ tRNA ml $\mathrm{m}^{-1}$ ), and extracted with $30 \mu \mathrm{l}$ alkaline phenol/chloroform. The aqueous phase was precipitated with 3 vols ethanol. The resulting pellet, after washing with $70 \%$ ethanol and Speed Vac drying, was suspended in $5 \mu \mathrm{l}$ Maxam loading buffer $(80 \%$ formamide; $1 \mathrm{mM}$ EDTA; $10 \mathrm{mM} \mathrm{NaOH} ; 0.05 \%$, w/v, bromphenol blue; $0.05 \%, \mathrm{w} / \mathrm{v}$, xylene cyanole FF). The DNA fragments were analysed on $6 \%$ DNA sequencing gels together with $\mathrm{G}+\mathrm{A}$ and $\mathrm{T}+\mathrm{C}$ sequencing ladders derived from the endlabelled fragments (Maxam \& Gilbert, 1980). After electrophoresis, the gels were dried and exposed to an X-ray film.

Expression of gapR in $\boldsymbol{E}$. coli. The $S$. aureofaciens gapR gene was mutated to introduce a single $\mathrm{NdeI}$ site in the translational start codon using a mutagenic primer, mut79 (5'-GTACGAGGTACATATGTGCGGCGCGG-3'). To produce $\mathrm{N}$-terminal His-tagged fusion GapR protein, the gene was cloned as a 1200 bp NdeI-SacI fragment in E. coli expression plasmid pET28a (Novagen) cut with the same enzymes, resulting in plasmid pET-gapR1. The DNA sequence of the fusion region was verified. The host strain for the $\mathrm{pET}$ series expression plasmids, E. coli BL21(DE3) pLysS, transformed with the plasmid, was grown in LB medium (Ausubel et al., 1987) containing $30 \mu \mathrm{g}$ chloramphenicol ml $\mathrm{m}^{-1}$ and $40 \mu \mathrm{g}$ kanamycin $\mathrm{ml}^{-1}$ at $30^{\circ} \mathrm{C}$ until $\mathrm{OD}_{600} 0 \cdot 5$. Expression was induced with $1 \mathrm{mM}$ IPTG. After $3 \mathrm{~h}$, the cells were harvested by centrifugation at $12000 \mathrm{~g}$ for $10 \mathrm{~min}$, and washed with icecold STE buffer. The pelleted cells were suspended in the binding buffer, and disrupted by sonication. The cell lysates were centrifuged for $30 \mathrm{~min}$ at $30000 \mathrm{~g}$, and the supernatants were stored in aliquots at $-70{ }^{\circ} \mathrm{C}$. The purification of Histagged GapR protein on His-Tag Bind resin (Novagen) under denaturing conditions was carried out as directed by the manufacturer.
Partial purification of GapR. E. coli cells containing pETgapR1 (2 g) were suspended in $10 \mathrm{ml}$ buffer A $(20 \mathrm{mM}$ Tris/HCl pH 8.6, 1 mM EDTA, $20 \mathrm{mM} \mathrm{KCl,} 12 \%$ glycerol, $5 \mathrm{mM}$ mercaptoethanol), and disrupted by sonication on ice. Following centrifugation at $15000 \mathrm{~g}$ for $30 \mathrm{~min}$, the supernatant was applied to a DEAE-cellulose column $(25 \mathrm{ml}$; DE 52 Whatman) equilibrated with buffer A. After the column had been washed with the buffer, proteins were eluted with a linear gradient of $\mathrm{KCl}$ from 0 to $1 \mathrm{M}$ in a total volume of $500 \mathrm{ml}$ at a flow rate of $1 \mathrm{ml} \mathrm{min}^{-1}$. Fractions containing DNA-binding activity $(24 \mathrm{ml})$ were pooled, concentrated and dialysed overnight against binding buffer. The sample was stored at $-70{ }^{\circ} \mathrm{C}$.

\section{RESULTS}

\section{Cloning and sequencing of the gapR gene}

We previously identified the $S$. aureofaciens gap gene encoding GAPDH. Sequence analysis of the region upstream of gap revealed the $3^{\prime}$ end of an incomplete gene encoding a protein similar to the AraC/XylS family of bacterial transcriptional regulators (Kormanec et al., 1995). In order to clone the complete gene, an $S$. aureofaciens CCM 3239 genomic library (2-4 kb TaqI partially digested chromosomal fragments cloned into the ClaI sites of pBR322) was hybridized with a $380 \mathrm{bp}$ TaqI-BamHI DNA fragment upstream of the gap gene (Kormanec et al., 1995). Two positive clones containing overlapping DNA fragments were identified, and the region 1272 bp upstream of gap was sequenced on both strands (Fig. 1a). Colinearity of the cloned DNA fragment with the $S$. aureofaciens chromosome was proved by Southern blot hybridization (data not shown). Analysis of the sequence by the program CODON 
(a)


(b)

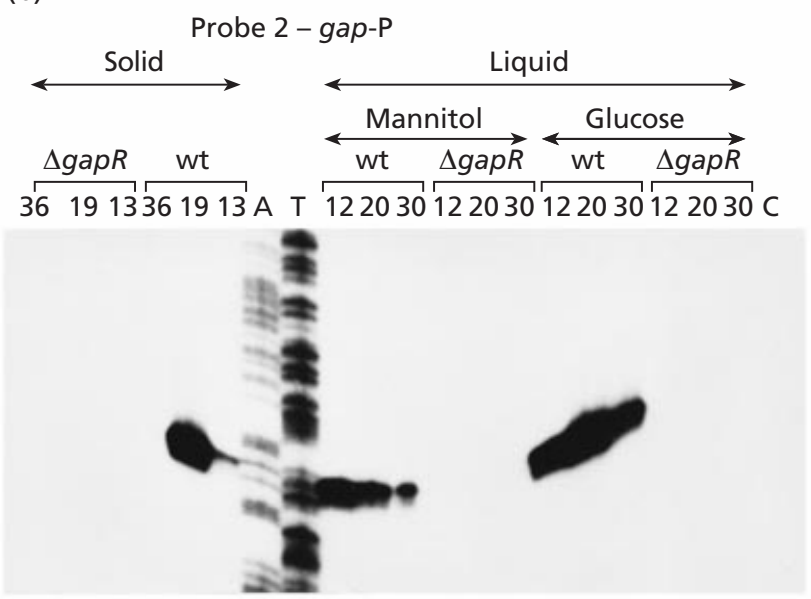

(c)

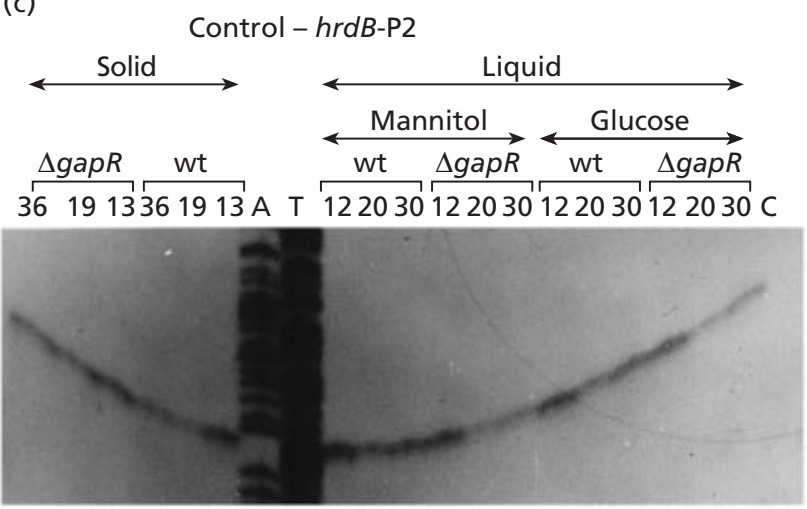

Fig. 3. High-resolution S1-nuclease mapping of the tsp for promoters directing expression of the $S$. aureofaciens gapR and gap genes. (a) Identification of the tsp for the gapRp promoter using probe 1 (Fig. 1a) in the $S$. aureofaciens wt strain. (b) Identification of the tsp for the gap-P promoter (Kormanec et al., 1997) using probe 2 (Fig. 1a) in the S. aureofaciens wt and $\triangle g a p R$ mutant strains. (c) Control S1-nuclease mapping experiment with the same RNA samples using a DNA probe for the $h r d B-P 2$ promoter (Kormanec \& Farkašovský, 1993). Lanes A and $T$ are $G+A$ and $T+C$ Maxam and Gilbert sequencing ladders (Maxam \& Gilbert, 1980). The lane numbers correspond to the time points at which mycelium was harvested for RNA isolation from cultures grown in liquid or solid media (see Methods). Lane C corresponds to E. coli tRNA used as a control in S1-nuclease mapping experiments. All S1-nuclease mapping experiments were performed twice using independent sets of RNA with similar results. In every experiment, the same RNA preparations were hybridized in parallel with both probes.
PREFERENCE (Wright \& Bibb, 1992) showed that the complete gene had a codon usage typical for Streptomyces genes (Wright \& Bibb, 1992). There are several in-frame potential start codons. The GTG codon at position 325 was considered the most likely start codon since it is preceded by a sequence (GGAGGT) showing similarity to a RBS (Baylis \& Bibb, 1987). The gene encodes a deduced protein of 278 aa and predicted molecular mass of $30014 \mathrm{Da}$. Based on its location and role in gap regulation (see below), we named the gene gapR. Comparison of the deduced GapR protein with databases revealed extensive sequence similarity to all members of the AraC/XylS family of transcriptional regulators, especially in the C-terminal DNA-binding domain (Gallegos et al., 1997). The S. aureofaciens GapR contains almost all residues of the AraC/XylS family signature motif (Gallegos et al., 1997). Like other members of the family, GapR was found to contain two $\alpha$-helix-turn- $\alpha$-helix DNA-binding motifs in the Cterminal region, at positions equivalent to those found in AraC (Fig. 2). Almost all members of the AraC/XylS family contain a conserved C-terminal DNA-binding domain, and nonconserved $\mathrm{N}$-terminal domain that is presumed to contain binding sites for activator molecules that confer specificity (Gallegos et al., 1997). It is striking that GapR is similar to two homologues of AraC/XylS predicted by the Streptomyces coelicolor genome sequencing project (www.sanger.ac.uk/ Projects/S_coelicolor/) and to the Streptomyces griseus A-factor-responsive transcriptional activator AdpA involved in streptomycin biosynthesis (Ohnishi et al., 1999) in this nonconserved N-terminal region (Fig. 2). The highest overall similarity was to the AraC/XylS homologue SC8F4.20c of S. coelicolor $(48.5 \%$ identical residues).

\section{Transcriptional analysis of the gapR gene}

To examine the expression of gapR, high-resolution S1nuclease mapping was performed using RNA isolated from surface-grown culture of $S$. aureofaciens during differentiation, and from a liquid-grown strain in the presence of glucose or mannitol as a carbon source. The $5^{\prime}$-labelled probe used for gapR is indicated in Fig. 1(a). A single RNA-protected fragment was identified with each RNA using probe 1 (Fig. 3a). The fragment corresponded to a putative promoter termed gapR $p$ with a tsp at $C$ (position 204), 120 bp upstream from the most likely translation initiation codon of gapR (Fig. 4a). The intensity of the fragment was comparable in RNA samples from cells grown on solid medium (Fig. 3a), suggesting a constitutive expression of gapR through differentiation. However, the level of RNA slightly increased at the end of exponential phase and in the presence of glucose in the cells grown in liquid medium (Fig. 3a). The -10 (TACGCT) and -35 (TAAACA) regions of the gapRp promoter partially match the consensus sequence of Streptomyces promoters recognized by a holoenzyme containing the principal $\sigma$ factor HrdB (Kang et al., 1997). Moreover, the gapRp-promoter-bearing DNA fragment was posi- 
(a)

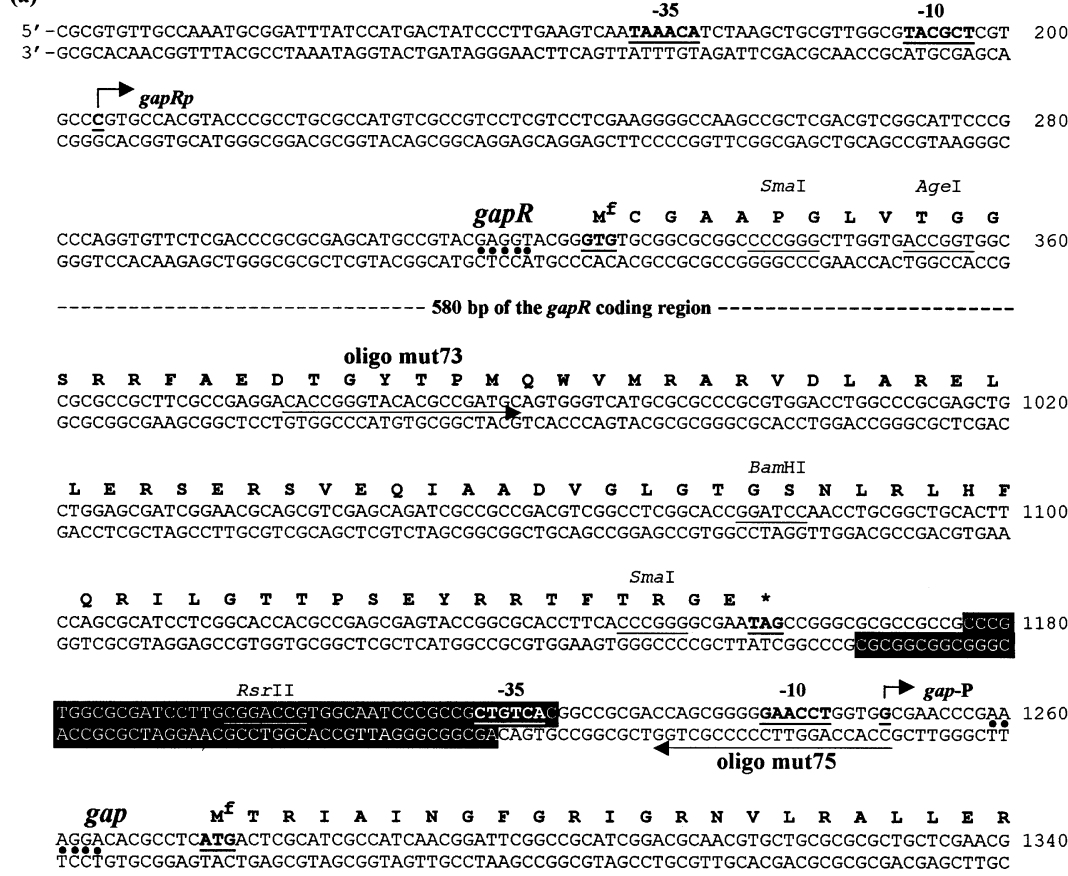

(b)

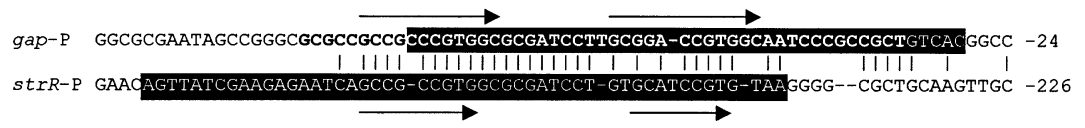

Fig. 4. (a) Nucleotide sequence of the $S$. aureofaciens gapRp and gap-P regions with flanking partial sequence of the genes. The deduced gapR and gap protein products are given in the single-letter amino acid code in the second position of each codon, with the stop codon marked by an asterisk. Presumptive RBSs are indicated by dots. The tsps of the corresponding promoters are indicated by bent arrows. The -10 and -35 boxes of promoters are in bold characters and underlined. Positions of the oligonucleotide primers for PCR amplification of a $291 \mathrm{bp}$ DNA fragment used for binding studies are designated by thin arrows below the corresponding DNA strands. The nucleotides that were protected from DNase I by GapR binding are shaded. Relevant restriction sites are indicated. The numbers refer to the deposited nucleotide sequence. The sequence of the whole $2731 \mathrm{bp}$ fragment has been deposited in GenBank/EMBL/DDBJ databases under accession number U21191. (b) Comparison of the GapR-binding site with the AdpA-binding site in the strR promoter (Vujaklija et al., 1993). The nucleotides that were protected from DNase I by GapR binding in the coding strand and by AdpA binding in the strR promoter (Vujaklija et al., 1993) are shaded. The nucleotides protected by GapR binding in the noncoding strand are in bold characters. Arrows indicate imperfect tandem repeats. The numbers refer to nucleotide position relative to the corresponding tsp. tive with the $S$. aureofaciens $h r d B$ gene in the E. coli twoplasmid system for identification of promoters recognized by a particular, heterologously expressed $\sigma$ factor of RNA polymerase (Nováková et al., 1998). These results suggest that the gapRp promoter could be recognized by the holoenzyme of RNA polymerase containing the principal $\sigma$ factor $\operatorname{HrdB}$.

\section{Disruption of the gapR gene in S. aureofaciens}

The chromosomal copy of gapR was inactivated by a double crossover (Kormanec et al., 1993). The thiostrepton-resistance marker $(t s r)$ replaced the $740 \mathrm{bp}$ SmaI-BamHI fragment internal to the gapR gene, removing most of the gapR coding region (aa 6-251). The resulting plasmid, pRPO7-11U, was used to transform $S$. aureofaciens protoplasts. In two thiostreptonresistant transformants, the integration occurred through a double crossover, resulting in the replacement of the wt gene by the disrupted allele (Fig. 1a). The correct integration was confirmed by Southern blot hybridization (Fig. 1b). The S. aureofaciens $\Delta g a p R$ strain was viable and stable. Growth of the mutant strain in solid rich and minimal media was comparable with the wt, irrespective of carbon source used (mannitol, glucose, maltose, citrate, oxalacetate, mannose, sucrose, arabinose, 2-oxoglutarate, lactose, galactose, acetate, glycerol). The mutant strain produced aerial mycelia and spores indistinguishable from those of the wt strain. The production of chlorotetracycline (Kormanec et al., 1993) was also not affected by the disruption. However, when grown in liquid minimal medium NMP (Hopwood et al., 1985), the growth rate of the $\Delta g a p R$ strain was partially decreased compared to the wt strain. At all time points after about $12 \mathrm{~h}$ postinoculation, the dry weights of the mycelium from $S$. aureofaciens $\Delta$ gapR were about $20 \%$ lower that those observed for the wt strain (data not shown).

\section{Expression of the gap gene in the $S$. aureofaciens $\Delta$ gapR mutant}

We have previously shown that a single gap-P promoter directing transcription of gap is induced both by glucose, and at the onset of aerial mycelium formation (Kormanec et al., 1997). To investigate whether gapR disruption has an effect on gap transcription, S1nuclease mapping was performed using RNA isolated from wt and $\Delta g a p R \quad S$. aureofaciens strains during differentiation on solid medium, and grown in liquid minimal medium NMP with mannitol or glucose as a carbon source to different growth phases (Fig. 3). As shown in Fig. 3(b), a single RNA-protected fragment corresponding to the gap-P promoter (Kormanec et al., 1997) was identified using probe 2 with the RNA isolated from the wt strain. The level of gap mRNA was substantially increased in the wt with glucose in the medium, and at the onset of aerial mycelium formation, 
(a)

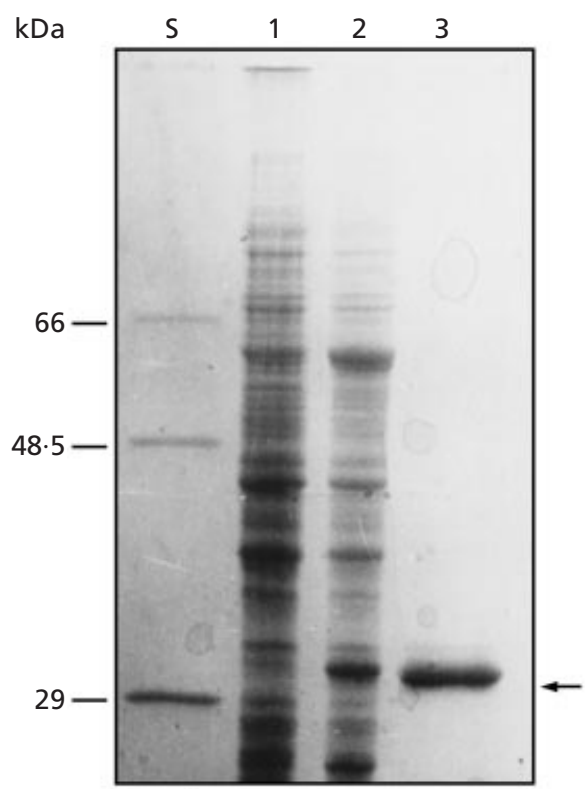

(b)

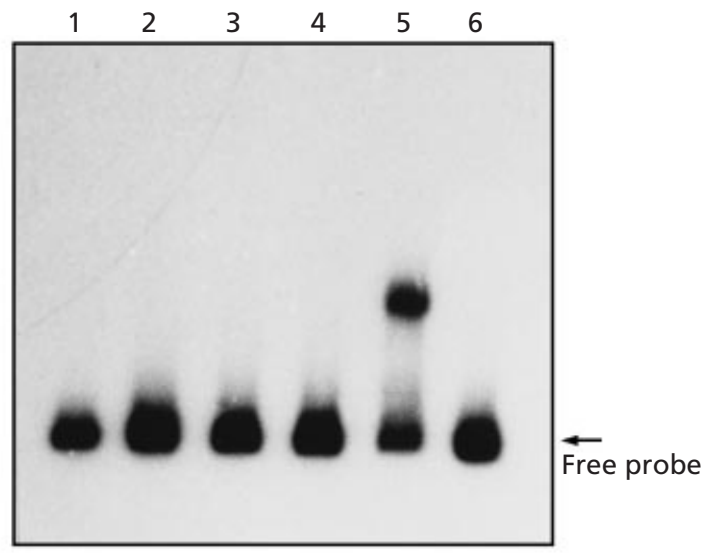

Fig. 5. (a) Overproduction of GapR in E. coli. Samples were analysed by SDS-PAGE ( $12.5 \%$ acrylamide). Lanes 1 and 2 contain crude extracts from E. coli BL21(DE3)pLysS carrying the corresponding plasmid, grown at $30^{\circ} \mathrm{C}$, and induced for $3 \mathrm{~h}$ with IPTG. Lanes: 1 , E. coli containing pET28a; 2, E. coli containing pET-gapR1; 3, purified denatured His-tagged GapR protein after $\mathrm{Ni}^{2+}$-affinity chromatography. The arrow indicates the location of the His-tagged GapR protein. Lane $\mathrm{S}$, molecular mass markers. (b) Gel mobility-shift assays of a 291 bp DNA fragment containing the gap-P promoter region (Fig. 1a) with cell-free extracts from E. coli overproducing GapR. The ${ }^{32} \mathrm{P}$-labelled DNA fragment ( 0.5 ng) was incubated with $15 \mu \mathrm{g}$ cell-free extracts from $E$. coli BL21(DE3)pLysS carrying pET28a before induction (lane 2) and $3 \mathrm{~h}$ after induction with IPTG (lane 3), and from E. coli BL21(DE3)pLysS carrying pET-gapR1 before induction (lane 4) and $3 \mathrm{~h}$ after induction with IPTG (lane 5). The specificity of binding is illustrated by addition of $50 \mathrm{ng}$ of the unlabelled 291 bp gap-P promoter DNA fragment (lane 6). Lane 1, the labelled fragment only. The arrow indicates the free DNA fragment.

as described previously (Kormanec et al., 1997). However, only a very weak RNA-protected fragment (visible after overexposure of the autoradiogram) was identified with all RNAs from the $\Delta g a p R$ mutant strain (Fig. 3b). Its intensity was comparable irrespective of carbon source used or stage of differentiation. The results indicate that the $\Delta g a p R$ mutation dramatically affected transcription from the gap-P promoter. The level of gap mRNA is much lower in the $\Delta g a p R$ mutant, irrespective of carbon source or developmental stage. As a control, S1-nuclease mapping was performed with the same RNA samples using a probe fragment specific for the $S$. aureofaciens hrdB-P2 promoter, which is expressed fairly constantly during differentiation (Kormanec \& Farkašovský, 1993). RNA-protected fragments corresponding to the $h r d B-\mathrm{P} 2$ promoter were identified with all RNA samples (Fig. 3c). Moreover, a similar pattern of gap-P expression to the wt was identified using RNA isolated from the $S$. aureofaciens $\Delta g a p R$ mutant strain with the gapR gene introduced in trans (data not shown).

These results were in contrast with the phenotype of the $\triangle g a p R$ mutant strain. GAPDH is an essential glycolytic enzyme for carbon flux in primary metabolism, and such a dramatic decrease of gap expression should strongly affect growth of the mutant strain on glycolytic carbon sources. However, the growth rate of the $\Delta g a p R$ mutant was only partially decreased (see above). Therefore, we measured phosphorylating GAPDH activity in cell-free extracts from the wt and $\Delta g a p R$ strains grown for $20 \mathrm{~h}$ in liquid minimal medium NMP with mannitol or glucose as a carbon source. Similar to results of transcriptional analysis, the specific activity of GAPDH was about 2.5 times higher in the presence of glucose $\left(4 \cdot 01 \pm 0.35 \mathrm{U} \mathrm{mg}^{-1}\right)$ than with mannitol (1.81 \pm $0 \cdot 22 \mathrm{U} \mathrm{mg}^{-1}$ ) in the wt strain. However, although glucose induction of GAPDH activity was detected in the $\Delta g a p R$ strains, the specific activity was decreased $\left(2 \cdot 6 \pm 0.28 \mathrm{U} \mathrm{mg}^{-1}\right.$ with glucose, and $1 \cdot 17 \pm 0 \cdot 12 \mathrm{U} \mathrm{mg}^{-1}$ with mannitol). The results clearly show that the $\triangle g a p R$ mutation also affects GAPDH activity, but $S$. aureofaciens seems to contain another glucose-inducible GAPDH-encoding gene, gapR-independent expression of which is sufficient to ensure growth. Our previous hybridization analysis suggested the presence of a second gap gene in S. aureofaciens (Kormanec et al., 1995).

\section{Overproduction of GapR in E. coli, and its binding to the gap promoter region}

To investigate whether GapR acts directly on gap-P induction, we overproduced this protein in E. coli and probed its binding in the gap-P promoter region. The $S$. 




Fig. 6. DNasel footprints of GapR binding to the $5^{\prime}$-end-labelled $291 \mathrm{bp}$ gap-P promoter DNA fragment (4 ng) (Fig. 1a). The vertical bars indicate the position of the GapR-binding site. The numbering is relative to the tsp of the gap-P promoter. Lane 1 is without the GapR protein sample. Lanes 2 and 3 contain 200 and $400 \mu \mathrm{g}$, respectively, of the His-tagged GapR protein, partially purified by DEAE-cellulose chromatography as described in Methods. Lanes $A$ and $T$ represent $G+A$ and $C+T$ Maxam-Gilbert sequencing ladders, respectively (Maxam \& Gilbert, 1980). All binding experiments were performed two times with independent sets of protein samples, and gave similar results.

aureofaciens GapR was overproduced as an N-terminal fusion with the $6 \times$ His tag in E. coli using a T7 RNA polymerase expression system. Total protein extracts of E. coli transformed with the plasmid pET-gapR1 and the cloning plasmid pET28a, before and after induction with IPTG at $30^{\circ} \mathrm{C}$, were examined by SDS-PAGE. A prominent band with increasing intensity (with a maximum after $3 \mathrm{~h}$ ) was clearly visible after induction with IPTG in the region corresponding to a molecular mass of $32 \mathrm{kDa}$ (Fig. 5a). This value corresponds to the calculated $M_{\mathrm{r}}$ of the $6 \times$ His-tagged GapR protein. However, almost all His-tagged GapR protein was found in the insoluble fraction. The amount of the soluble form did not significantly increase at lower temperature, or after coexpression with groEL, groES or trx genes (data not shown). We also failed to renaturate the $6 \times$ His-tagged GapR protein isolated under denaturating conditions by $\mathrm{Ni}^{2+}$-affinity chromatography, employing various conditions. This insolubility is a typical characteristic of regulators within the AraC/XylS family and has hampered the biochemical analysis of these proteins (Gallegos et al., 1997). However, when soluble cell-free protein extracts of $E$. coli transformed with plasmid pET-gapR1 and pET28a, respectively, were used in a gel retardation assay with the ${ }^{32}$ P-labelled 291 bp gap-P promoter DNA fragment (positions -290 to $+1 \mathrm{bp}$, in relation to the tsp of the gap-P promoter; Fig. 1a), a retarded band was clearly visible only with the cell-free extracts of E. coli containing plasmid pET-gapR1 (Fig. 5b). The specificity of the interaction was demonstrated by the competitive binding of the unlabelled fragment (Fig. 5b, lane 6). These results indicate that a small residual portion of GapR is in a soluble form and is capable of binding to the gap-P promoter region. However, we were unable to purify it by $\mathrm{Ni}^{2+}$-affinity chromatography under native conditions.

To map the binding site for GapR within the gap-P promoter fragment, the ${ }^{32} \mathrm{P}$-labelled $291 \mathrm{bp}$ gap-P promoter DNA fragment was digested with restriction endonucleases, and purified fragments (Fig. 1a) were used in gel mobility-shift assays. Assays with an RsrIIdigested fragment $(-54$ to +1$)$ showed no binding of GapR. Assays with a SmaI-digested fragment ( -99 to +1 ) revealed a similar binding activity of GapR protein to that of the whole fragment. To locate this GapRbinding site in the gap-P promoter region, DNaseI footprinting assays were carried out using the same $291 \mathrm{bp}$ gap-P promoter fragment, 5'-end-labelled at either end. To increase specific activity of GapR, we used GapR protein partially purified by DEAE-cellulose chromatography (as described in Methods). Using the coding strand, we found that the region from -73 to $-28 \mathrm{bp}$ upstream of the tsp was protected. Using the noncoding strand, we found that the region from -82 to $-33 \mathrm{bp}$ was protected (Fig. 6). These results are in agreement with the gel mobility-shift experiments. The position of the binding site is indicated in Fig. 4.

\section{DISCUSSION}

A new homologue of the AraC/XylS family of regulatory proteins, GapR, regulates expression of the gap gene in $S$. aureofaciens. This conclusion is based on the following experimental data: (i) transcription of the gap gene was dramatically reduced in the $S$. aureofaciens 
$\triangle g a p R$ mutant strain; (ii) gapR disruption decreased levels of GAPDH activity; (iii) GapR specifically binds to the gap promoter region. Although AraC/XylS homologues (more than 100 are known) are involved in the regulation of various processes (for instance, they control degradation of sugars such as arabinose, cellobiose, melibiose, raffinose, rhamnose and xylose, certain amino acids and alcohols, and they regulate stress response and pathogenesis; Gallegos et al., 1997), S. aureofaciens GapR is the first AraC/XylS homologue that is essential for the expression of a gene encoding a glycolytic enzyme.

Recent experiments in Gram-negative E. coli and lowGC Gram-positive B. subtilis revealed that the expression of gap is induced by glucose. However, this induction is caused by different mechanisms in these bacteria. In E. coli, glucose induction of both gap genes, gap $A$ and gapB, depends upon a component of the PTS system, the EII ${ }^{\mathrm{Glc}}$ protein. However, this dependence is indirect. Glucose is assumed to function as an external signal modulating the phosphorylation state of EII ${ }^{\mathrm{Glc}}$, which transmits the signal to the yet unknown regulator (Charpentier et al., 1998). In B. subtilis, two gap genes were identified encoding GAPDHs with opposite physiological roles: glycolytic gapA and gluconeogenic gapB. While gap $A$ is induced, gapB is strongly repressed by glucose (Fillinger et al., 2000). This glucose induction of the glycolytic gapA is indirectly dependent on the catabolite control protein CcpA (Fillinger et al., 2000; Tobisch et al., 1999). The glycolytic gapA gene is coexpressed in an operon with the upstream gene $c g g R$, which encodes a repressor of the $\operatorname{cgg} R-g a p A$ operon. CggR belongs to the SorC/DeoR family of transcriptional regulators. The activity of this repressor is inhibited by glucose, and it is assumed that the role of CcpA in glucose induction is mediated by $\mathrm{CggR}$ (Fillinger et al., 2000). Likewise, expression of gap is also induced by glucose in high-GC Gram-positive $S$. aureofaciens (Kormanec et al., 1997). However, in contrast to $B$. subtilis, the glycolytic gap gene is monocistronic in $S$. aureofaciens (Kormanec et al., 1997), and an activator protein of the AraC/XylS family, GapR, which directly binds to the gap promoter region, regulates its expression. Considering S1-nuclease mapping experiments in $S$. aureofaciens wt and $\Delta g a p R$ mutant strains, transcription of gap is substantially reduced in the $\triangle g a p R$ mutant, irrespective of carbon source used for cultivation. Only a very low residual amount of gap mRNA was detected in the mutant strain, visible only after overexposure of the gel. Based on these results, it seems that the GapR protein is absolutely required for gap transcription. The mechanism of glucose induction in S. aureofaciens still remains unclear. However, GapR protein may ensure gap expression at an uninduced level, irrespective of the carbon source used. In the presence of glucose, an unknown signal might be transduced to the GapR protein by mechanisms similar to those previously described for E. coli or B. subtilis (Charpentier et al., 1998; Fillinger et al., 2000). Such modified GapR might ensure induced gap expression.
In addition to the glucose induction, the gap-P promoter is induced at the onset of aerial mycelium formation (Kormanec et al., 1997), and this induction is also substantially decreased in the $\Delta g a p R$ mutant. A possible explanation for this induction might be connected with the phase I glycogen degradation that occurs in the course of Streptomyces differentiation in substrate hyphae that undergo aerial mycelium formation (Homerová et al., 1996; Plaskitt \& Chater, 1995). Thus, GapR might respond to a common product of glucose and glycogen catabolism that is present in increased amounts either in a high glucose uptake in substrate mycelium grown in the presence of glucose, or after phase I glycogen degradation at the beginning of aerial mycelium formation. It is assumed that glycogen accumulation and degradation may play a role in morphological differentiation (Homerová et al., 1996; Plaskitt \& Chater, 1995), and this proposed linking of gap-P induction indicates physiological relevance of regulation of glycolysis in connection with differentiation.

Considering the results of the DNaseI footprinting analysis, the proposed binding site of GapR in the gap$P$ promoter spans a region from -73 to -28 bp (for the coding strand), and -82 to -33 bp (for the noncoding strand) (Fig. 4a). This protected region contains a tandem repeat (Fig. 4b) that could be the GapR-binding consensus sequence. Moreover, a similar tandem repeat was identified in the proposed binding site of the $S$. griseus AraC/XylS homologue AdpA, in the strR promoter (Ohnishi et al., 1999; Vujaklija et al., 1993) (Fig. 4b). Based on these preliminary binding studies, it is difficult to suggest a consensus element for the GapRbinding site. However, considering the similarity between these two proposed binding sites for GapR and AdpA, this tandem repeat might constitute a consensus sequence of the GapR-binding site. No similarity to any of the other identified binding sites for AraC/XylS transcriptional activators was found, but binding sites for this family are highly variable and, in general, unique for each homologue (Gallegos et al., 1997). The GapRprotected region overlaps the -35 hexamer of the gap$\mathrm{P}$ promoter. Thus, surface residues of GapR, like those of many activators, could contact RNA polymerase. This binding is similar to several other activators of AraC/XylS (Gallegos et al., 1997).

Considering the comparison of GapR with other AraC/ $\mathrm{XylS}$ homologues (Fig. 2), it is conceivable that this type of gap regulation also exists in other Streptomyces species, since two AraC/XylS-homologous proteins discovered by genome sequencing of $S$. coelicolor (www.sanger.ac.uk/Projects/S_coelicolor/) are very similar to GapR in the N-terminal domain. This domain is generally responsible for an effector binding, and AraC/XylS homologues that are similar in this domain also have similar functions (Gallegos et al., 1997). Searching the nucleotide sequence around these two $S$. coelicolor genes did not reveal any gap gene or other glycolytic gene. However, one of these proteins might 
activate expression of a gap gene located in a different position in the S. coelicolor genome. Based on the present data of the genome sequencing project, $S$. coelicolor also contains two gap orthologues. However, we did not find any similarity between the $S$. aureofaciens gap-P promoter (including the GapRbinding site) and the regions upstream from the $S$. coelicolor gap orthologues. An intriguing finding was the high sequence similarity between $S$. aureofaciens GapR and AdpA of S. griseus (Ohnishi et al., 1999) in this $\mathrm{N}$-terminal region (Fig. 2). The AdpA protein is an A-factor-responsive transcriptional activator of the AraC/XylS family, which binds to the promoter of the pathway-specific regulatory gene strR responsible for transcription of streptomycin biosynthetic genes in $S$. griseus. Disruption of adpA affected streptomycin biosynthesis and morphological differentiation in S. griseus (Ohnishi et al., 1999; Vujaklija et al., 1993). This phenotype is in contrast with the results of gapR disruption, which did not affect sporulation and production of secondary metabolites in S. aureofaciens. Thus, it seems that these two proteins are not homologous in their function. Moreover, compared to other AraC/XylS homologues, S. griseus AdpA has an extraordinary long C-terminal DNA-binding domain (Fig. 2). In this respect, it is interesting that the binding sites of both proteins (GapR and AdpA) are similar (Fig. 4b). This might reflect sequence similarity of these proteins in proposed $\alpha$-helix-turn- $\alpha$-helix DNA-binding domains (Fig. 2).

An interesting finding was that, though gap transcription was substantially reduced in the $\Delta g a p R$ mutant, the mutation only partially affected growth of $S$. aureofaciens, irrespective of carbon source used. Estimation of GAPDH activity actually revealed a decrease of enzyme activity in the $\Delta g a p R$ mutant, but the residual activity was still high enough to ensure growth. These results indicate the presence of a second gap gene in $S$. aureofaciens, as was also suggested by hybridization studies (Kormanec et al., 1995). Based on the residual GAPDH activity in cell-free extracts in the $\Delta g a p R$ mutant, the second gap gene seems to be induced by glucose.

\section{ACKNOWLEDGEMENTS}

We would like to thank Mrs Renáta Knirschová for excellent technical assistance, and Luboš Klučar for computational assistance. This work was supported by Grant 2/7001/20 from the Slovak Academy of Sciences.

\section{REFERENCES}

Alefounder, P. R. \& Perham, R. N. (1989). Identification, molecular cloning and sequence analysis of a gene cluster encoding the class II fructose 1,6-bisphosphate aldolase, 3-phosphoglycerate kinase and a putative second glyceraldehyde-3-phosphate dehydrogenase of Escherichia coli. Mol Microbiol 3, 723-732.

Ausubel, F. M., Brent, R., Kingston, R. E., Moore, D. O., Seidman, J. S., Smith, J. A. \& Struhl, K. (1987). Current Protocols in Molecular Biology. New York: Wiley.
Baylis, H. A. \& Bibb, M. J. (1987). The nucleotide sequence of a $16 \mathrm{~S}$ rRNA gene from Streptomyces coelicolor A3(2). Nucleic Acids Res 15, 1716.

Boschi-Muller, S., Azza, S., Pollastro, D., Corbier, C. \& Branlant, G. (1997). Comparative enzymatic properties of GapB-encoded erythrose-4-phosphate dehydrogenase of Escherichia coli and phosphorylating glyceraldehyde-3-phosphate dehydrogenase. $J$ Biol Chem 272, 15106-15112.

Bradford, M. M. (1976). A rapid and sensitive method for the quantitation of microgram quantities of protein utilizing the principle of protein-dye binding. Anal Biochem 72, 248-254.

Branlant, G., Flesch, G. \& Branlant, C. (1983). Molecular cloning of the glyceraldehyde-3-phosphate dehydrogenase genes of Bacillus stearothermophilus and Escherichia coli, and their expression in Escherichia coli. Gene 25, 1-7.

Byers, L. D. (1982). Glyceraldehyde-3-phosphate dehydrogenase from yeast. Methods Enzymol 89, 326-335.

Charpentier, B. \& Branlant, C. (1994). The Escherichia coli gapA gene is transcribed by the vegetative RNA polymerase holoenzyme $\mathrm{E} \sigma^{70}$ and by the heat shock RNA polymerase $\mathrm{E} \sigma^{32}$. J Bacteriol 176, 830-839.

Charpentier, B., Bardey, V., Robas, N. \& Branlant, C. (1998). The $\mathrm{EII}^{\mathrm{GlC}}$ protein is involved in glucose-mediated activation of Escherichia coli gapA and gapB-pgk transcription. J Bacteriol 180, 6476-6483.

Chater, K. F. (1998). Taking a genetic scalpel to the Streptomyces colony. Microbiology 144, 1465-1478.

Della Seta, F., Boshi-Muller, S., Vignais, M. L. \& Branlant, G. (1997). Characterization of Escherichia coli strains with gapA and gapB genes deleted. J Bacteriol 179, 5218-5221.

Fillinger, S., Boschi-Muller, S., Azza, S., Dervyn, E., Branlant, G. \& Aymerich, S. (2000). Two glyceraldehyde 3-phosphate dehydrogenases with opposite physiological roles in a nonphotosynthetic bacterium. J Biol Chem 275, 14031-14037.

Gallegos, M.-T., Schleif, R., Bairoch, A., Hofmann, K. \& Ramos, J. L. (1997). AraC/XylS family of transcriptional regulators. Microbiol Mol Biol Rev 61, 393-410.

Harris, J. I. \& Waters, M. (1976). Glyceraldehyde-3-phosphate dehydrogenase. In The Enzymes, vol. XIII, pp. 1-49. Edited by P. D. Boyer. New York: Academic Press.

Homerová, D., Benada, O., Kofroňová, O., Řežuchová, B. \& Kormanec, J. (1996). Disruption of a glycogen branching enzyme gene, $g \lg B$, specifically affects the sporulation-associated phase of glycogen accumulation in Streptomyces aureofaciens. Microbiology 142, 1201-1208.

Hopwood, D. A., Bibb, M. J., Chater, K. F. \& 7 other authors (1985). Genetic Manipulation of Streptomyces: a Laboratory Manual. Norwich: The John Innes Foundation.

Horinouchi, S., Hara, O. \& Beppu, T. (1983). Cloning of a pleiotropic gene that positively controls biosynthesis of A-factor, actinorhodin, and prodigiosin in Streptomyces coelicolor A3(2) and Streptomyces lividans. J Bacteriol 155, 1238-1248.

Kang, J.-G., Hahn, M.-Y., Ishihama, A. \& Roe, J.-H. (1997). Identification of sigma factors for growth phase-related promoter selectivity of RNA polymerases from Streptomyces coelicolor A3(2). Nucleic Acids Res 25, 2566-2573.

Kormanec, J. (2000). Analyzing the developmental expression of sigma factors with S1-nuclease mapping. In Nuclease Methods and Protocols. Methods in Molecular Biology, pp. 498-513. Edited by C. H. Chein. Totowa, NJ: Humana Press. 
Kormanec, J. \& Farkašovský, M. (1993). Differential expression of principal sigma factor homologues of Streptomyces aureofaciens correlates with the developmental stage. Nucleic Acids Res 21, 3647-3652.

Kormanec, J., Řežuchová, B. \& Farkašovský, M. (1993). Optimization of Streptomyces aureofaciens transformation and disruption of the $h r d A$ gene encoding a homologue of the principal $\sigma$ factor. J Gen Microbiol 139, 2525-2529.

Kormanec, J., Lempelová, A., Farkašovský, M. \& Homerová, D. (1995). Cloning, sequencing and expression in Escherichia coli of a Streptomyces aureofaciens gene encoding glyceraldehyde-3phosphate dehydrogenase. Gene 165, 77-80.

Kormanec, J., Lempel'ová, A., Nováková, R., Řežuchová, B. \& Homérová, D. (1997). Expression of the Streptomyces aureofaciens glyceraldehyde-3-phosphate dehydrogenase gene (gap) is developmentally regulated and induced by glucose. Microbiology 143, 3555-3561.

Kormanec, J., Ševčíková, B., Sprušanský, O., Benada, O., Kofroňová, O., Nováková, R., Řežuchová, B., Potúčková, L. \& Homérová, D. (1998). The Streptomyces aureofaciens homologue of the $w h i B$ gene is essential for sporulation and its expression correlates with the developmental stage. Folia Microbiol 43, 605-612.

Laemmli, U. K. (1970). Cleavage of structural proteins during assembly of the head of bacteriophage T4. Nature 227, 680-685.

Maxam, A. M. \& Gilbert, W. (1980). Sequencing end-labelled DNA with base specific chemical cleavages. Methods Enzymol 65, 449-560.
Nováková, R., Ševčíková, B. \& Kormanec, J. (1998). A method for the identification of promoters recognized by RNA polymerase containing a particular sigma factor : cloning of a developmentally regulated promoter and corresponding gene directed by the Streptomyces aureofaciens sigma factor RpoZ. Gene 208, 43-50.

Ohnishi, Y., Kameyama, S., Onaka, H. \& Horinouchi, S. (1999). The A-factor regulatory cascade leading to streptomycin biosynthesis in Streptomyces griseus: identification of a target gene of the A-factor receptor. Mol Microbiol 34, 102-111.

Plaskitt, K. A. \& Chater, K. F. (1995). Influences of developmental genes on localized glycogen deposition in colonies of a mycelial procaryote, Streptomyces coelicolor A3(2): a possible interface between metabolism and morphogenesis. Philos Trans $R$ Soc Lond B 347, 105-121.

Tobisch, S., Zuhlke, D., Bernhardt, J., Stulke, J. \& Hecker, M. (1999). Role of CcpA in regulation of the central pathways of carbon catabolism in Bacillus subtilis. J Bacteriol 181, 6996-7004.

Vujaklija, D., Horinouchi, S. \& Beppu, T. (1993). Detection of an A-factor-responsive protein that binds to the upstream activation sequence of $s t r R$, a regulatory gene for streptomycin biosynthesis in Streptomyces griseus. J Bacteriol 175, 2652-2661.

Wright, F. \& Bibb, M. J. (1992). Codon usage in the $\mathrm{G}+\mathrm{C}$ rich Streptomyces genome. Gene 113, 55-65.

Received 4 October 2000; revised 9 January 2001; accepted 29 January 2001. 